\title{
HPLC-UV Determination of Catechins and Gallic Acid in Aerial Parts of Astragalus glycyphyllos L.
}

\author{
Lysiuk Roman $^{1}$ and Kozachok Solomiia ${ }^{2}$ \\ ${ }^{1}$ Department of Pharmacognosy and Botany, Danylo Halytsky Lviv National Medical University \\ Pekarska Str., 69, Lviv, 79010, Ukraine \\ ${ }^{2}$ Department of Pharmacognosy and Medical Botany, I.Horbachevsky Ternopil State Medical University \\ Ruska Str., 36, Ternopil, 46002, Ukraine
}

(Received: March 10, 2019; Accepted: June 16, 2019; Published (web): December 19, 2019)

\begin{abstract}
The aerial part of Astragalus glycyphyllos L. (Astragali glycyphylli herba), a promising nephroprotective agent in folk medicine, has been investigated by HPLC-UV for occurrence of catechins, which are known in individual state as renoprotective substances and gallic acid. The following six compounds were detected and quantitatively determined in the analyzed plant material: (-)-gallocatechin, (-)-epigallocatechin, (+)-catechin, (-)-epicatechin, (-)-epicatechin gallate and gallic acid. The highest yield amongst the flavan-3-ols was found for (-)-gallocatechin $(3.7 \mathrm{mg} / \mathrm{g})$ and (-)-epigallocatechin $(1.7 \mathrm{mg} / \mathrm{g})$. The determined content of gallic acid was $0.4 \mathrm{mg} / \mathrm{g}$. The investigated material should be subjected for further studies to substantiate the recommendation for its wider employment in current phytotherapeutic practice.
\end{abstract}

Key words: Astragalus glycyphyllos, HPLC-UV, nephroprotectors, catechins, gallic acid.

\section{INTRODUCTION}

Medicinal plants remain one of important source of valuable remedies, due to their effectiveness, safety and possibility of long-term administration, a wide range of constituents and modes of application. Amongst thousands of plant species around the world, only a small part has been investigated. Number of phytopharmaceuticals in recent years increases worldwide that might be demonstrated as well by occurrence of large number of new monographs on herbal drugs in various pharmacopoeias; incorporation of these monographs is due to recent substantiation of efficiency of these herbal drugs, development and implementation of their standardization criteria.

Astragalus glycyphyllos L., also known as liquorice milk vetch or wild liquorice, is a promising folk medicine remedy. ${ }^{1-3}$ The plant parts are considered as a potential source of dietary supplements.

Correspondence to: Lysiuk Roman

E-mail: pharmacognosy.org.ua @ukr.net

Tel: +38-093-65-888-53

Dhaka Univ. J. Pharm. Sci. 18(2): 241-247, 2019 (December)

DOI: https://doi.org/10.3329/dujps.v18i2.44464 pharmaceutical and nutraceutical products. ${ }^{3}$ Liquorice milk vetch is a perennial herbaceous legume, widespread throughout Europe, except the extreme north. $^{4}$

Flavonoids and saponins are active specific metabolites of the plant species. ${ }^{1,5}$ Wild liquorice contains vitamins, minerals and antioxidant substances. ${ }^{6}$ Butkute et al. ${ }^{3}$ consider that the plant is a valuable source of iron, phenolic substances and isoflavones. ${ }^{7}$ Earlier, we reported ${ }^{8,9}$ the presence and quantity content of hydroxycinnamic acids and monosaccharides in its aerial parts.

Folk medicine applies the remedies from roots and leaves of the plant due to its refreshing, purifying, diuretic, and other benefits. ${ }^{2,3}$ The infusions of A. glycyphyllos acts as a diuretic and its aqueous alcoholic extracts exhibit antibacterial effects. The plant leaves and seeds are applied in urolithiasis and oliguria in the Caucasus. The decoction of its aerial portion is applied in the Carpathians as a diuretic remedy in urolithiasis and other diseases of the kidneys and urinary tract. ${ }^{2}$ 
A. glycyphyllos extract had a hepatoprotective effect, comparable to silymarin, on hepatic antioxidant defense system in in vivo model of carbon tetrachloride liver damage in rats $^{1}$ and acted as a free radical scavenger and $\mathrm{Fe}^{2+}$ chelator. ${ }^{3,7}$

Flavan-3-ols are a group of polyphenols, widely distributed in the plant kingdom. Their monomers are the basic component units of oligomers and polymers often called condensed tannins, characterized by their typical astringency taste. ${ }^{10}$ Catechins are known as the major building blocks of tannins and may be found in the seeds and skins of fruits which are not fully ripened. ${ }^{11}$

Proanthocyanidins, or flavan-3-ols, are end products of the flavonoid biosynthetic pathway, which nowadays attract significant attention due to their health-protective effects, including anticancer, immunomodulatory, antimutagenic, antioxidant, cardiopreventive, antimicrobial, antiviral, and neuroprotective ones. ${ }^{10,12,13}$ Flavan-3-ols showed great potential for the treatment of lifestyle related diseases, such as type 2 diabetes, obesity, and metabolic syndrome. Catechins were also reported to have effects on slowing down the aging progress as well as on prevention of Alzheimer's disease, cardiovascular disease, and cancer. ${ }^{10}$ Anti-inflammatory effects of proanthocyanidins, observed in epidemiological studies, are exerted by modulation of cell redox status and inhibition of signaling pathways as NF- $\kappa B$ activation. $^{14}$ De Pascual-Teresa et $a l .{ }^{15}$ reviewed health benefits of catechins and proanthocyanidins to cardiovascular and metabolic health. ${ }^{15}$ Epigallocatechin gallate acts as a hepatoprotective agent, since it restores ethanol-induced alterations in hepatic detoxification system. ${ }^{16}$

Catechins are able to prevent oxidation of proteins and low-density lipoprotein, possess anti-atherosclerotic and antidiabetic activity, block the platelet aggregation. ${ }^{10,11}$ Antioxidant and antimicrobial effects of green tea catechins and crude extracts of teas are known. ${ }^{17,18}$ Catechin and epicatechin demonstrated antioxidant activity more effective than $\alpha$-tocopherol or ascorbate. ${ }^{19}$ Catechins are powerful agents for protecting the body against reactive oxygen species. ${ }^{20}$

Several investigations have been dedicated to green tea polyphenols as the antimutagenic, anticarcinogenic and apoptotic agents. ${ }^{18}$ Anticancerogenic properties of green tea extract are related to the presence of catechins, especially of epigallocatechin 3-gallate, which show a strong inhibitory properies in angiostatic urokinase activity ${ }^{18}$, significantly inhibit hypoxia- and serum-induced HIF- $1 \alpha$ protein accumulation in human cervical carcinoma and hepatoma cells ${ }^{21}$, activate the second phase detoxication enzymes. The benefits of green tea consumption have been corroborated in animal studies of cancer chemoprevention, artherosclerosis, Parkinson's disease, Alzheimer's disease, and other aging-related ailments. ${ }^{22}$ Gallocatechin was isolated from guava leaves as a bio-antimutagenic compound against UV-induced mutation in Escherichia coli. ${ }^{23}$

In a clinical study ${ }^{24}$ it has been demonstrated, that increased consumption of proanthocyanidins was associated with better renal function. High proanthocyanidin consumers were at $50 \%$ lower risk of moderate chronic kidney insufficiency, and $65 \%$ lower risk of experiencing a 5-year renal disease event. Condensed tannins (proanthocyanidins) of cranberries are responsible for preventing uropathogenic phenotypes of P-fimbriated $E$. coli from adhering to the urinary tract. ${ }^{25}$

In continuation of our investigation on detection and quantification of pharmacologically important groups of phenolic compounds in aerial part of Astragalus glycyphyllos L. (Astragali glycyphylli herba $)^{9,26}$, with an objective to develop a new herbal drug, as a part of its further standardization process, we have carried out determination of catechins totality in above-ground organs of liquorice milk vetch, considering possible contribution of these polyphenols into a total nephroprotective (hypoazotemic) activity of the subjected folk medicine remedy. 


\section{MATERIALS AND METHODS}

Plant material collection. The samples of the herbal drug Astragali glycyphylli herba, consisting of the above-ground parts of A. glycyphyllos L., were harvested from wild plots in the city of Lviv $\left(49^{\circ} 79^{\prime} 15^{\prime \prime} \mathrm{N}, 24^{\circ} 04^{\prime} 15^{\prime \prime} \mathrm{E}\right)$ during flowering stage in June 2017. The collected specimens were identified by O.O. Kagalo, PhD (Biol.), Institute of Ecology of the Carpathians of the NAS of Ukraine (Lviv), in accordance with morphological descriptions of the plant $^{4}$

Preparation of the plant extract. Dried and powdered herb of A. glycyphyllos (1 gm) was extracted by boiling with $50 \mathrm{~cm}^{3}$ of demineralized water (Simplicity SIMSV00 Water Purification System Millipore) for 30 minutes. The extract was filtered and quantitatively transferred into the $50 \mathrm{~cm}^{3}$ volumetric flask; volume was adjusted with demineralized water. The obtained solution was carefully mixed, filtered through a cellulose membrane filter with a pore size of $0.45 \mu \mathrm{m}$ into a HPLC vial and directly injected.

Equipment and chromatographic separation conditions. Analysis of catechins and gallic acid in aerial part of A. glycyphyllos was performed on the Agilent 1200 Series HPLC system with photodiode array detector (G1315C), equipped with flow degasser (G1322A), autosampler (G1329A), column thermostat (G1316A) and PC software Agilent ChemStation. For the separation of the studied compounds, discovery $\mathrm{C}_{18}$ HPLC Column 5 $\mu \mathrm{m}$ particle size, $\quad$ L $\times$ I.D. $25 \mathrm{~cm} \times 4.6 \mathrm{~mm}$ (Supelco-504971) with the precolumn $20 \mathrm{~mm}$ filter at $25{ }^{\circ} \mathrm{C}$ was applied. Mobile phase was composed of 0,1 $\% \mathrm{v} / \mathrm{v}$ trifluoroacetic acid in $5 \% \mathrm{v} / \mathrm{v}$ of acetonitrile solution (A) and $0,1 \% \mathrm{v} / \mathrm{v}$ trifluoroacetic acid in acetonitrile (B) at a flow rate $0.5 \mathrm{ml} / \mathrm{min}$ with the following stepwise gradient elution program (Table 1):

Scanning speed 0,6 s; detection wavelength (190-400 nm) was set at $280 \mathrm{~nm}$ with a total run time $40 \mathrm{~min}$. Sample injections were performed employing an autosampler; sample volume - $10 \mu \mathrm{m} .^{27}$
Catechins and gallic acid were identified by comparing their UV-spectra and retention time with analytical standards data. As standards (-) epigallocatechin (EGC, Supelco, № 49037-U), (+) catechin (C, Supelco, № 49040-U), (-) epicatechin (EC, Supelco, № 49045-U), (-) epicatechin gallate (ECG, Supelco, № 49060-U), (-) gallocatechin (GC, Supelco, № 49069-U), gallic acid (GA, Supelco, № 5995-86-8) were used.

Table.1. Gradient elution program characteristics, applied for determination of catechins and gallic acid.

\begin{tabular}{ccc}
\hline Time, $\min$ & A, \% & B, \% \\
\hline 0.00 & 100 & 0 \\
1.00 & 100 & 0 \\
8.00 & 88 & 12 \\
10.00 & 88 & 12 \\
15.00 & 75 & 25 \\
20.00 & 75 & 25 \\
25.00 & 25 & 75 \\
28.00 & 25 & 75 \\
29.00 & 100 & 0 \\
\hline
\end{tabular}

Quantities of the studied compounds were evaluated by constructing a calibration curve using plotted peak area versus mass concentration of each standard in triplicate using 5 different values of concentration.

\section{RESULTS AND DISCUSSION}

As a result of the performed HPLC-UV analysis of water extract from the herb of A. glycyphyllos, 5 individual catechins and gallic acid (Figures 1, 2; Table 2) were identified and quantified.

Lobanova (2010) quantified totality of catechins, expressed as catechin, in A.glycyphyllos herb by the spectrophotometric method in various morphological groups of samples, collected in 2007 and 2008 in suburb of Novosibirsk (the Russian Federation) during all vegetation periods. ${ }^{28}$ Seeds had the highest yield - $0,25 \%$ dried mass (DM) in the beginning of the fruiting stage; the content of catechins in the leaves varied from $0,14 \%$ to $0,21 \%$, in stems $0,03 \%-0,11 \%$, pericarps $0,04-0,10 \%$, in 
flowers it reached $0,11 \%$ in the beginning of flowering period. ${ }^{28}$

Total flavonoid content in licorice milk vetch herb samples from Republic of Macedonia was 1.62 mg catechin equivalent/g DM, total phenolic content $-15,93 \mathrm{mg}$ gallic acid equivalent/g DM. ${ }^{29}$
Butkute et $a l .{ }^{3}$ established the lower detectable content of condensed tannins in the samples from young $A$. glycyphyllos plants (LOQ was $3.2 \mathrm{mg}$ catechin equivalents $\left.\mathrm{g}^{-1} \quad \mathrm{DM}\right){ }^{30}$ The total phenolic concentration in aerial plant parts of A. glycyphyllos was determined ( $18.5 \mathrm{mg}$ gallic acid equivalents $\mathrm{g}^{-1}$ at flowering and $17.1 \mathrm{mg} \mathrm{GAE} \mathrm{g}^{-1}$ at branching stage). ${ }^{7}$

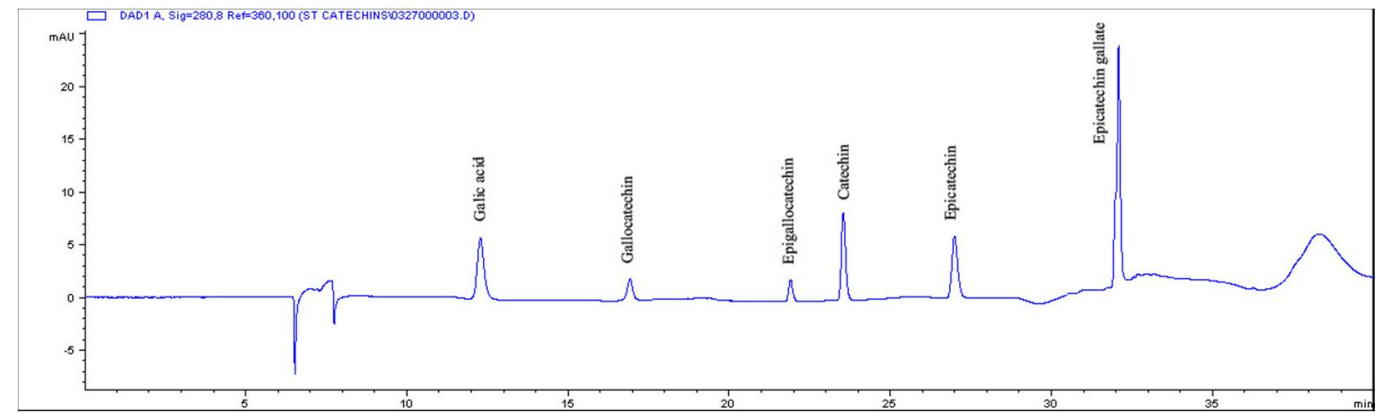

Figure 1. HPLC-UV chromatogram of the mixture of standards of catechins and gallic acid at $280 \mathrm{~nm}$.

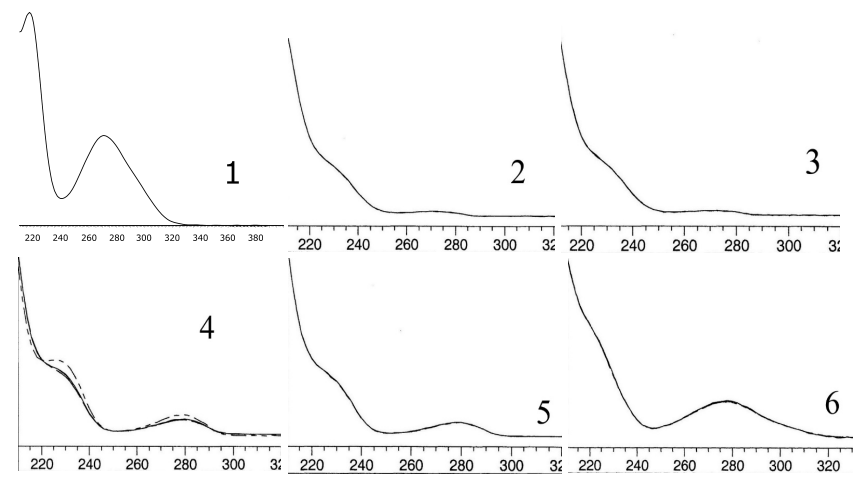

Figure 2. UV spectra of the mixture of standards of catechins and gallic acid at $280 \mathrm{~nm}: 1$ - gallic acid; 2 - gallocatechin; 3 - epigallocatechin; 4 - catechin; 5 - epicatechin; 6- epicatechin gallate.

Table 2. The content of catechins and gallic acid in Astragali glycyphylli herba.

\begin{tabular}{|c|c|c|c|c|}
\hline № & $\mathrm{RT}, \min$ & $\lambda, \mathrm{nm}$ & Compound & Amount, mg/g \\
\hline 1 & 12.30 & 280 & Gallic acid & 0.4 \\
\hline 2 & 16.74 & 280 & (-)-Gallocatechin & 3.7 \\
\hline 3 & 21.55 & 280 & (-)-Epigallocatechin & 1.7 \\
\hline 4 & 23.19 & 280 & (+)-Catechin & 0.2 \\
\hline 5 & 26.17 & 280 & (-)-Epicatechin & 0.5 \\
\hline 6 & 31.69 & 280 & (-)-Epicatechin gallate & 0.2 \\
\hline \multicolumn{4}{|c|}{ Total } & 6.7 \\
\hline
\end{tabular}

The nephroprotective effect of polyphenols can be ascribed to their potent reactive oxygen species scavenging and metal chelating properties, mitigation of subsequent biochemical, morphological, and functional renal damage. ${ }^{31}$ Green tea extract protected rats against the nephrotoxicity induced by contrast 
media. ${ }^{32}$ The significant protective effect of green tea extract (containing 75\% catechins with 50\% epigallocatechin gallate) against alcohol-induced renal damage in rats $^{33}$ was shown by Reddyvari et al. ${ }^{33}$ the catechin mixture reduced plasma creatinine and urea levels in nephrotoxin treated animals. Protective effect of catechin in an experimental model of myoglobinuric acute renal failure in rats was demonstrated. ${ }^{34}$ The substance reduced the toxicity of myoglobin in the renal tissues; the creatinine and urea clearance, which was markedly reduced by intramuscular injection of glycerol, was significantly improved by catechin treatment. ${ }^{34}$ Catechin extract from Camellia sinensis leaves after induction of nephrotoxicity by gentamicin in rabbits had nephroprotective effects as it reduced the elevation in nonenzymatic kidney markers - serum urea and creatinine, compared with gentamicin group. ${ }^{35}$ Epigallocatechin gallate (EGCG) significantly protected renal function and free radical-mediated injury in the kidney of rodents from cyclosporine A induced changes. Levels of blood urea nitrogen (BUN), creatinine clearance and serum creatinine were lower in EGCG-treated group, than in group treated with the nephrotoxic agent ${ }^{36}$

Pretreatment of rats with catechin markedly attenuated renal dysfunction, caused by ferric nitrilotriacetate, normalized the renal morphological alterations and restored the depleted renal antioxidant enzymes. ${ }^{37}$ Catechin $(100 \mathrm{mg} / \mathrm{kg} / \mathrm{day}$; for 21 days $)$ attenuated cyclosporine $\mathrm{A}$ - induced renal dysfunction in rats. Co-administration of catechin along with the nephrotoxic agent significantly reduced the lipid peroxidation and restored the decreased glutathione levels as compared with CsA alone group. ${ }^{38}$ (-) Epicatechin-3-O-gallate suppressed glomerular cell proliferation and the increase of urinary protein excretion in 5/6 nephrectomised rats. ${ }^{39}$ (-)-Epigallocatechin 3-O-gallate from green tea exerts protective activity in rats with chronic renal failure, resulting in suppression of $\mathrm{Cr}$ oxidation. ${ }^{40}$

Renoprotective effect of grape seed extract treatment was established ${ }^{41}$ in ethylene glycol induced nephrotoxic mice through an improvement of antioxidant status and significant decrease of urinary lactate dehydrogenase and lipid peroxidation.

Grape seed proanthocyanidin extract protected in mice the renal function from cisplatin-induced nephrotoxicity, significantly decreased the level of blood urea nitrogen, serum creatinine and showed limited histopathological damage, comparing with the group, treated with nephrotoxin alone. ${ }^{42}$ Nishioka et $a l .{ }^{43}$ investigated the ability of proanthocyanidin-based products from grape seeds and pine bark, and (+) catechin and (-)-epigallocatechin 3-O-gallate to modulate the $\mathrm{KBrO} 3$ - induced renal toxicity. These flavon-3-ol products restored lipid peroxidation to the level in the untreated rats, lowered $\mathrm{KBrO}_{3}$-induced BUN level and the increased level of the creatinine. ${ }^{43}$ The nephroprotective effects of proanthocyanidn-BPI, extracted from seeds of grapes, was demonstrated in experimental glycerol-induced myoglobinuric acute renal failure in rats. ${ }^{44}$ In the same experimental model the rats which received proanthocyanidins from seeds of grape, in addition to glycerol, had signifcantly lower blood urea and serum creatinine levels compared to those receiving the nephrotoxin alone. ${ }^{45}$

It should be noted that A. glycyphyllos contains flavon-3-ols, which demonstrated hypoazotemic effects in several animal studies on various models of renal damage. ${ }^{34,35,43}$

\section{CONCLUSIONS}

Sufficient natural resources of the promising plant material A. glycyphylli herba and its yield of catechins, which act as renoprotective agents, caused the neccessity to carry out an analysis of these active principles in the subjected herb.

The outcomes of the current research demonstrate that samples of aerial parts of licorice milk vetch, collected in Ukraine, yielded 5 identified catechins and gallic acid. The content of individual catechins ranged from $0,2 \mathrm{mg} / \mathrm{g}$ to $3,7 \mathrm{mg} / \mathrm{kg}$.

Considering the research outcomes, the investigated material should be subjected for further studies to substantiate the recommendation for its wider employment in current phytotherapeutic 
practice, as well as a nephroprotective (hypoazotemic) agent.

\section{REFERENCES}

1. Shkondrov, A., Simeonova, R., Kondeva-Burdina, M., Vitcheva, V. and Krasteva, I. 2015. Study to evaluate the antioxidant activity of Astragalus glycyphyllos extract in carbon tetrachloride-induced oxidarive stress in rats. Eur. J. Med. Plants 2, 59-66.

2. Lysiuk, R. and Darmohray, R. 2016. Pharmacology and Ethnomedicine of the Genus Astragalus. Int. J. Pharmacol. Phytochem. Ethnomed. 3, 46-53. (10.18052/www. scipress. com/IJPPE.3.46)

3. Butkute, B., Dagilyte, A., Benetis, R., Padarauskas, A., Ceseviliene, J., Olšauskaite, V. and Lemeziene, N. 2018. Mineral and phytochemical profiles and antioxidant activity of herbal material from two temperate Astragalus Species. Biomed. Res. Int. Article ID 6318630, 11 p. (https://doi.org/10.1155/2018/6318630)

4. Tutin, T.G., Heywood, V.H., Burges, N.A., Moore, D.M., Valentine, D.H., Walters, S.M. and Webb, D.A. (Eds). 1981. Flora Europaea. Vol.2. Rosaceae to Umbelliferae. Cambridge University Press, Cambridge - London - New York - New Rochelle - Melbourne - Sydney, p. 115.

5. Krasteva, I., Benbassat, N. and Nikolov, S. 2000. Flavonoids from genus Astragalus L. Pharmacia 3-4, 20-25.

6. Lobanova, I.E. 2011. Phytochemical characteristic of Astragalus glycyphyllos (Fabaceae) [in Russian]. Plant Life Asian Russ. 1, 87-90.

7. Butkutė, B., Lemežienė, N., Dagilytė, A., Cesevičienė, J., Benetis, R., Mikaliūnienè, J. and Rodovičius, H. 2016. Mineral Element and Total Phenolic Composition and Antioxidant Capacity of Seeds and Aerial Plant Parts of Perennial Legumes. Commun. Soil Sci. Plant Anal. 47 suppl.1, 36-45. (10.1080/00103624.2016.123202)

8. Lysiuk, R., Skibitska, M. and Stecko, M-P. 2015. LC/MS Determination of monosaccharides contents in above-ground portions of Astragalus glycyphyllos L. Med. forum 6, 66- 69.

9. Lysiuk, R., Kozachok, S. and Darmohray, R. 2016. HPLC analysis of hydroxycinnamic acids from the aerial parts of Astragalus glycyphyllos L. In: Agrobiodiversity for Improving Nutrition, Health and Life Quality, 2016. Scientific Proceedings of the International Network AgroBioNet (Brindza, J. and Klymenko S., Eds.). Slovak University of Agriculture, Nitra, Slovakia, pp. 250-254.

10. Ma, C.M. and Hattori, M. 2009. Flavan-3-ol Monomers and Condensed Tannins in Dietary and Medicinal Plants. In: Flavonoids: Biosynthesis, Biological Effects and Dietary Sources (Keller R. B., Ed.), Nova Science Publishers, Inc., New York, pp. 273-289.
11. Brodowska, K.M. 2017. Natural flavonoids: classification, potential role, and application of flavonoid analogues. Eur. J. Biol. Res 2, 108-123.

12. Dixon, R.A., Xie, D.Y. and Sharma, SB. 2005. Proanthocyanidins - a final frontier in flavonoid research? New Phytol. 1, 9-28.

13. Aron, P.M. and Kennedy, J.A. 2008. Flavan-3-ols: nature, occurrence and biological activity. Mol. Nutr. Food Res. 1, 79-104.

14. Mena, P., Domínguez-Perles, R., Gironés-Vilaplana, A., Baenas, N., García-Viguera, C. and Villaño D. 2014. Flavan-3-ols, anthocyanins and inflammation. IUBMB Life 11, 745-758. (10.1002/iub.1332)

15. de Pascual-Teresa, S., Moreno, D.A. and Garcia-Viguera C. 2010. Flavanols and anthocyanins in cardiovascular health: a review of current evidence. Int. J. Mol. Sci. 11, 1679-1703. (10.3390/ijms11041679)

16. Anuradha, C.V. and Kaviarasan, S. 2007. (-) Epigallocatechin gallate restores ethanol-induced alterations in hepatic detoxification system and prevents apoptosis. Orient. Pharm. Exp. Med. 3, 311-320.

17. Sroka, Z. 2005. Antioxidative and antiradical properties of plant phenolics. Z. Naturforsch C. 11-12, 833-843.

18. Gramza, A., Korczak, J. and Amarowicz, R. 2005. Tea polyphenols - their antioxidant properties and biological activity - a review. Pol. J. Food Nutr. Sci. 3, 219-235.

19. Rice-Evans, C.A., Miller, N.J., Bolwell, P.G., Bramley, P.M. and Pridham, J.B. 1995. The relative antioxidant activities of plant- derived polyphenolic flavonoids. Free Radic. Res. 4, 375-383.

20. Saxena, M., Saxena, J. and Pradhan, A. 2012. Flavonoids and Phenolic acids as antioxidants in plants and human health. Int. J. Pharm. Sci. Rev. Res. 2, 130-134.

21. Zhang, Q., Tang, X., Lu, Q., Zhang, Z., Rao, J. and Le, A.D. 2006. Green tea extract and (-)-epigallocatechin- 3-gallate inhibit hypoxia- and serum-induced HIF-1alpha protein accumulation and VEGF expression in human cervical carcinoma and hepatoma cells. Mol. Cancer Ther. 5, 1227-38.

22. Zaveri, N.T. 2006. Green tea and its polyphenolic catechins: medicinal uses in cancer and noncancer applications. Life Sci. 18, 2073-2080.

23. Matsuo, T., Hanamure, N., Shimoi, K., Nakamura, Y. and Tomita, I. 1994. Identification of (+)-gallocatechin as a bio-antimutagenic compound in Psidium guava leaves. Phytochemistry 4, 1027-1029.

24. Ivey, K.L., Lewis, J.R., Lim, W.H., Lim, E.M., Hodgson, J.M. and Prince, L.R. 2013. Associations of proanthocyanidin intake with renal function and clinical outcomes in elderly women. PLOS ONE 8, e71166. (10.1371/journal.pone. 0071166). 
25. Howell, A.B. 2007. Bioactive compounds in cranberries and their role in prevention of urinary tract infections. Mol. Nutr. Food Res. 6, 732-737.

26. Lysiuk, R. and Hudz, N. 2017. Differential spectrophotometry: Application for quantification of flavonoids in herbal drugs and nutraceuticals. Int. J. Trends Food Nutr. 1, e102.

27. Shostak, L.G., Marchyshyn, S.M., Kozachok, S.S. and Karbovska, R.V. 2016. Investigation of phenolic compounds of Primula veris L. J. Educ. Health Sport 5, 424-432.

28. Lobanova, I. E. 2010. The Contents of Flavonoids and Saponins in Above-Ground Part of Astragalus glycyphyllos $\mathrm{L}$. [in Russ]. Vestn. Novosib.gos. univ., Ser.: biol. klin. med. 1, 70-73.

29. Tusevski, O., Kostovska, A., Iloska, A., Trajkovska, L. and Gadzovska, S.S. 2014. Phenolic production and antioxidant properties of some Macedonian medicinal plants. Cent. Eur. J. Biol. 9, 888-900. (10.2478/s11535-014-0322-1).

30. Butkutè, B., Benetis, R., Padarauskas, A., Cesevičienè, J., Dagilytè, A., Taujenis, L., Rodovičius, H. and Lemežienė, N. 2017. Young herbaceous legumes - a natural reserve of bioactive compounds and antioxidants for healthy food and supplements. J. Appl. Bot. Food Qual. 90, 346-353. (10.5073/JABFQ.2017.090.043)

31. Singh, D., Kaur, R., Chander, V. and Chopra, K. 2006. Antioxidants in the prevention of renal disease. J. Med. Food 4, 443-450.

32. Nasri, H., Hajian, S., Ahmadi, A., Baradaran, A., Kohi, G., Nasri, P. and Rafieian-Kopaei, M. 2015. Ameliorative effect of green tea against contrast-induced renal tubular cell injury. Iran. J. Kidney Dis. 6, 421-426.

33. Reddyvari, H., Bulle, S., Vaddi, D.R. and Varadacharyulu, N.Ch. 2016. Ameliorative effect of green tea extract on alcohol induced renal damage in rats. Int. J. Appl. Biol. Pharm. Techn. 3, 23-31. (10.21276/ijabpt.2016.7.3.4)

34. Chander, V., Singh, D. and Chopra, K. 2003. Catechin, natural antioxidant protects against rhabdomyolysis- induced myoglobinuric acute renal failure. Pharmacol. Res. 5, 503-509.

35. Ibrahim, D.A. and Albadani, R.N. 2014. Evaluation of the Potential Nephroprotective and Antimicrobial Effect of Camellia sinensis Leaves versus Hibiscus sabdariffa (in vivo and in vitro Studies). Adv. Pharmacol. Sci. 389834. (10.1155/2014/389834).
36. Chang, E.J. and Mun, K.C. 2004. Effect of epigallocatechin gallate on renal function in cyclosporine-induced nephrotoxicity. Transplant. Proc. 7, 2133-2134.

37. Chopra, K., Singh, D. and Chander, V. 2004. Nephrotoxicity and its prevention by catechin in ferric nitrilotriacetate promoted oxidative stress in rats. Hum. Exp. Toxicol. 23, 137-143.

38. Anjaneyulu, M., Tirkey, N. and Chopra, K. 2003. Attenuation of cyclosporine-induced renal dysfunction by catechin: possible antioxidant mechanism. Ren. Fail. 5, 691-707.

39. Fujitsuka, N., Kurogi, A., Hattori, T. and Shindo, S. 1997. Effects of onpi-to (TJ-8117) and (-) epicatechin3 -O-gallate on the proliferating changes in glomeruli of $5 / 6$ nephrectomized rats [in Japanese]. Nihon Jinzo Gakkai Shi 7, 693-700.

40. Nakagawa, T., Yokozawa, T., Sano, M., Takeuchi, S., Kim Mujo and Minamoto, S. 2004. Activity of (-)-Epigallocatechin 3-O-gallate against oxidative stress in rats with adenine-induced renal failure. J. Agric. Food Chem. 52, 2103-2107.

41. Mohanasundari, M., Sabesan, M. and Sethupathy, S. 2005. Renoprotective effect of grape seeds extract in ethylene glycol induced nephrotoxic mice. Indian J. Exp. Biol. 4, 356-359.

42. Gao, Z., Liu, G., Hu, Z., Li, X., Yang, X., Jiang, B. and Li, X. 2014. Grape seed proanthocyanidin extract protects from cisplatin-induced nephrotoxicity by inhibiting endoplasmic reticulum stress-induced apoptosis. Mol. Med. Rep. 3, 801-807. (10.3892/mmr.2014.1883)

43. Nishioka, H., Fujii, H., Sun, B. and Aruoma, O.I. 2006. Comparative efficacy of oligonol, catechin and (-)-epigallocatechin 3-O-gallate in modulating the potassium bromate-induced renal toxicity in rats. Toxicology 2-3, 181-187.

44. Avramovic, V., Vlahovic, P., Mihailovic, D. and Stefanovic, V. 1999. Protective effect of a bioflavonoid proanthocyanidin-BP1 in glycerol-induced acute renal failure in the rat: Renal stereological study. Ren. Fail. 6, 627-634.

45. Stefanovic, V., Savic, V., Vlahovic, P., Cvetkovic, T., Najman, S. and Mitic-Zlatkovic, M. 2000. Reversal of experimental myoglobinuric acute renal failure with bioflavonoids from seeds of grape. Ren. Fail. 3, 255-266. 